a parallactic displacement superposed on a rectilinear proper motion, in particular if the star and an invisible companion are revolving around their common centre of mass, this procedure is not adequate. If it is in fact carried out (as it will be, in a routine observation, since we shall have no a priori knowledge of the presence of a companion), the residuals found from the measurements at the various epochs will show a systematic trend. The discovery of periodicities in certain parallax residuals was announced some years ago, but as has been recently pointed out $^{1}$, spurious periods of about two years are obtain able from almost all parallax measurements. They are indeed to be expected from general considerations: the method of reduction will tend to balance a large accidental residual at any epoch by residuals of the opposite sign a year earlier and a year later. Some recent work on two frequently observed stars, however, is based on accurate data extending back over some decades, and points very strongly to the presence of companions the mass of which is so small that they would be more accurately described as plansts than as stars. It so happens that both these stars are visual binaries, so that the newly discovered companions make them into triple systems.

The system 61 Cygni consists of two sixth-magnitude stars making in 720 years a complete revolution in a large orbit with a semi-major axis of 25 seconds of arc. Extensive photographic observations of high accuracy, made over nearly thirty years, now reveal ${ }^{2}$ small deviations from Keplerian motion which can only be explained by assuming that a third invisible component of small mass revolves around one of the main components. If the measurements are reduced on the assumption that the system consists of only two components, residuals are obtained which show a well-marked periodicity both in Right Ascension and in Declination, the period being 4.9 years and the amplitudes about $0 \cdot 01^{\prime \prime}$. The measurements are made only on the relative positions of the visual components $A$ and $B$, so there is no way of knowing to which of them the perturbing member $C$ is attached. However, the masses of $A$ and $B$ obtained from their known luminosities are practically identical, so that whichever is used in conjunction with the dynamical elements of the small orbit, the same result is obtained : the mass of $O$ is only 0.016 times that of the sun, and the semi-major axis of its orbit is only $2 \cdot 4$ astronomical units (that is, $2 \cdot 4$ times that of the earth). The orbit is so eccentric that at periastron this invisible planet must come within 0.7 astronomical units of its primary. Allowance for the perturbation introduced by the third body removes the systematic trend of the residuals and halves their mean value. We have thus strong evidence for the existence in the 6I Cygni system of a body of mass only about sixteen times that of Jupiter. This is little more than one tenth that of the lightest known star (Krüger $60 B$, mass 0.14 sun), and the claim that. the new companion should be regarded as a planet rather than as a star is evidently very weighty.

The other binary system in which a component of planetary mass has just been discovered ${ }^{3}$ is 70 Ophiuchi. This consists of two stars of magnitudes 4.3 and 6.0 revolving in a relative orbit of period eighty-eight years and semi-major axis rather less than $5^{\prime \prime}$. Careful study of photographs taken over a period of nearly thirty years shows periodic deviations from this binary orbit, the observations suggesting a secondary period of seventeen years and amplitudes of about $0.015^{\prime \prime}$ in both $X$ and $Y$ co-ordinates. Again it is impossible to know to which of the main components the perturbing body is attached, but this time $A$ and $B$ are of rather different mass. If the planet revolves around $A$ (mass $1 \cdot I$ sun) the orbital radius will be 6.8 astronomical units and the mass of the invisible component 0.012 sun. If it is attached to $B(0.7$ sun) the radius of its orbit will be 5.9 astronomical units and its own mass only 0.008 sun. Here again, then, we have a third body, in what had hitherto been regarded as a binary system, with a mass of about one hundredth that of either of the visual components. In this case the claim of the newly discovered body to be regarded as a planet is even stronger: its mass is only about ten times that of Jupiter.

The state of astronomy is now such that by extending the programme of parallax observations somewhat, invisible planetary companions not much more massive than Jupiter could be discoverad if they are in fact attached to the nearer stars. If systematic observations for this purpose were instituted by international co-operation after the War, it could be decided within a relatively short time whether planetary systems are or are not a rare cosmic phenomenon. A definitive answer to this long-standing query would obviously have an important bearing on theories of the origin of our own solar system.

1 Jackson, J., Mon. Not. Roy. Ast. Soc., 102, 257 (1942).

- Strand, K. Aa, Pub. Ast. Soc. Pacif., 55, 29 (Feb. 1943). See also NATURE, 151, 283 (1943).

Reuyl, D., and Holmberg, E., Astrophys. J., 97, 41 (Jan. 1943).

\section{UNITED NATIONS CONFERENCE ON FOOD AND AGRICULTURE}

A BRIEF summary of the report and a list of A attending delegates and of resolutions passed at the United Nations Conference on Food and Agriculture held at Hot Springs, Virginia, during May 18-June 3 has been published by H.M. Stationery Office*. The Conference was attended by delegations from forty-four countries. The British delegation of nine was under the chairmanship of $\mathrm{Mr}$. Richard Law, Under-Secretary of State for Foreign Affairs.

"The Conference met to consider the goal of freedom from want in relation to food and agriculture. In its resolutions zind its reports, the Conference has recognized that freedom from want means a secure, adequate and suitable supply of food for every man."

Freedom from want, the Conference declared, means more than freedom from hunger, but the attainment of the latter is a first essential step towards the attainment of the greater, ultimate good. The Conference recognized that to free the entire population of the world from hunger or malnutrition would require a greatly increased production of foodstuffs, but saw no insuperable technical obstacles to achieving the required level of production. Assuming that such obstacles as have existed in the past could and would be overcome by the technical ingenuity of man, the Conference proceeded to consider the less tractable problems of social and political organizations, on the solution of which the realization of universal freedom from want ultimately depends.

The results of the deliberations are contained in a series of thirty-odd resolutions, the text of which

* Final Act of the United Nations Conference on Food and Agriculture. Cmd. 6451. (Iondon: H.M. Stationery Offlce, 1943.) 9d. net. 
comprises the main part of the publication. A full report of the Conference has, apparently, been prepared, and reference is made to it, but it has not yet been published.

The first resolution is in the form of a declaration that the first task of the United Nations, after winning the War, will be to free the peoples of the world from hunger. The full attainment of this goal must be a long process, but essential thereto are greatly increased food production and economic regimes which ensure to all sufficient purchasing power to buy their necessary food. The responsibility that the people have enough food for health and wellbeing lies with the several nations, but each nation can fully attain the goal only if all work together. The resolutions of the Conference were framed to suggest the kind of machinery that might be set up to promote international collaboration in this vitally important field, and the kind of tasks with which the machinery will have to deal and to which it must be adapted.

The most important resolution of the Conference is that which recommends the setting up of a permanent international organization to promote such measures of food production and agriculture as will raise the levels of nutrition and standards of living of the peoples of the world. Recognizing the urgency of making a start, the Conference recommends the immediate setting up in Washington of an interim commission on which each of the participating Governments was invited to designate a representative before July 15, 1943. The interim commission would automatically dissolve when the permanent commission was established.

The main purpose of the interim commission would be to draw up and submit for the consideration of the participating Governments plans for the form and functions of the permanent organization. It would also formulate a declaration embodying the obligations of each nation to collaborate in the improvement of agriculture and in raising the standard of nutrition. Each Government would be invited to subscribe to this declaration.

The two paragraphs outlining the proposed scope and functions of the permanent organization are important enough to be quoted in full :

"That in the preparation of a plan for the permanent organization the Interim Commission give full consideration to the following:

(a) The relation of the permanent organization to, and methods of associating it with, other institutions, national as well as international, which already cxist, or which may hereafter be established, and other fields ;

(b) Provision for membership in the permanent organization, in due course, of governments not representcd on the Interim Commission;

"That in considering the functions and duties to be assigned to the permanent organization the Interim Commission take into account

(a) The promotion of scientific, technological, social and economic research;

(b) The collection and dissemination of information and pro(b) The collection and dissemination
vision for the exchange of services ;

(c) The submission to member governments and authorities of recommendations for action with regard to the following:

(i) Nutrition;

(ii) Standards of consumption of food and other agricultural products

(iii) Agricultural production, distribution and conservation;

(iv) Statistics and economic studies in the field of agriculture and food, including the study of the relation of agriculture to world economy ;

(v) Education and extension work in the fleld of food and agriculture;

(vi) Agricultural credit ;

(vii) Problems of agricultural population and farm labor."

A further extension of the functions of the permanent organization into the fields of commodity control, agricultural co-operative movements and land tenure is also tentatively proposed.

$\mathrm{It}$ is this permanent organization, to be devised by the interim commission, which will give effect to, or provide the machinery whereby the several Governments can jointly give effect to, the resolutions of the Conference and other measures afterwards designed to bring the ultimate goal of the Conference nearer attainment.

The Conference further recommends that the several Governments should formally declare their intentions immediately to take measures to increase the food resources and to improve the diets of their peoples in accordance with the principles and objectives outlined at the Conference.

The fourth resolution recommends that Governments should undertake positive measures to improve the diets of 'vulnerable' social groups, namely pregnant and nursing women, children and large families in low-income groups.

Resolution $\mathrm{V}$ recommends that, whereas a diet at a level merely sufficient to prevent malnutrition is not enough to promote health and well-being, Governments should actively encourage the study of health in relation to nutrition and the dissemina. tion of knowledge of correct feeding. Resolution VI refers to the prevalence of certain deficiency diseases and the need for taking measures to eliminate them and to prevent their recurrence.

Assuming that measures are taken to improve diets and to eliminate deficiency diseases, the Conference reccmmends (Resolution VII) that national nutrition organizations bo established to ascertain the food-consumption habits and nutritional status of different sections of the population, with authority to make recommendations in the light of their findings. Resolution VIII recommends that these organizations periodically and freely exchange information and experience among themselves, and report the results of their investigations to the permanent commission ; and Resolution $\mathrm{X}$ that the work and experience of organizations already existing for similar purposes should be fully used, whenever possible.

Resolution IX recommends that the goal of food policy in each country should be the optimal diet in quantity and quality, and that Governments should distinguish clearly between this goal and the more immediate goal of minimal diets; at which in many cases they will first have to aim.

Resolution XI recommends that the permanent commission considers questions relating to the production of certain non-food marine and agricultural products, especially those on which some countries ill-adapted to produce their own food depend as a main source of income.

Resolution XII recommends that, as a first step in overcoming the general shortage of food, every effort should be made by countries the agriculture of which can be expanded in the short-term period to increase the acreage under crops for direct human consumption, and even to hold back the rebuilding of depleted livestock herds as well as the production of other crops which compete for acreage with essential foods. This recommendation is made to both those countries where agriculture has, and those where agriculture has not, been impaired by the War. The Conference recognized that the first and most vital task for all will be to eliminate the post-war hunger that will ravage so much of the world. In order to make the best use of the inadequate supplies of food, fertilizers, agricultural machinery, etc., that 
will be available for some years after the War, it is further recommended (Resolution XIII) that the several Governments affirm the principle of mutual responsibility for the increased production of essential foodstuffs to the utmost capacity of each country, the effective distribution of such foodstuffs, the prevention of speculation in food and other necessities under the anticipated conditions of scarcity, and the radual adjustment of national agricultures to secure balanced expansion of production and consumption throughout the world.

Resolutions XIV and XV deal with the changeover from a short-term to a long-term agricultural policy. As a working basis the Conference recommends that national farming systems should be adapted to the natural and economic factors of the environment, and should be designed so as to maintain soil fertility and provide steady employment throughout the year. In general, this implies the adoption of mixed rota. tional farming. The evolution of such systems must be paralleled by the development of programmes of education and research and the provision, where needed, of technical assistance and adequate credit to the producers.

Resolution XVI makes specific recommendations for ensuring an adequate supply of credit to agriculture, and Resolution XVII stresses the importance of establishing farmer co-operative societies in all countries. Resolution XVIII recommends that surveys be made of existing systems of land texture. Resolution XIX enlarges on the importance of providing agriculture with efficient educational, research and technical services.

Resolution XX refers to soil erosion as "the greatest physical danger to the world's food production", and recommends that each nation undertakes the necessary economic and other measures to conserve its soil and water resources, while the permanent commission formulates the principles of soil conservation and facilitates the interchange between nations of conservation experts. Resolution XXI deals with the development and settlement of unproductive lands by drainage, irrigation, soil ameliora. tion, etc. The permanent commission would perform a co-ordinating and controlling function similar to that envisaged in Resolution XX.

Resolution XXII recommends the development of subsidiary industries, internationally controlled emigration, and financial assistance in the intensification of agriculture in regions suffering from rural overpopulation.

Resolution XXIII recommends in the interest of international security the removal of barriers to the expansion of international trade.

Resolution XXIV makes suggestions for achieving an economy of abundance that read rather like an election manifesto. Resolution XXV recommends that the broad principles be formulated upon which international commodity arrangements should be based in order that such arrangements will contribute to the well-being of the peoples of the world, and proposes that an international organization be created for this purpose and to co-ordinate the operation of such arrangements in accordance with the principles agreed upon.

Resolutions XXVI and XXVII recommend special national and international measures for wider food production; special attention being given to the feeding of "vulnerable" groups and the making available of protective foods to all.

Resolution XXVIII recommends that the per- manent commission investigates the practicability, and fosters the adoption, of international grade standards for agricultural and marine commodities with a view to a general improvement in the marketing and quality of food products. A wide extension of market research is advocated, and the taking of steps by the Governments concerned to protect both the producer and the consumer of food against the practices of those who regard them as legitimate prey.

Resolution XXIX recommends that the permanent commission studies the technical, scientific and economic problems of food processing, storage and distribution, and that steps be taken by each country to make full use of new technological processes developed since the War. Resolution XXX urges that the margins between the price to the producer and cost to the consumer be reduced by whatever means are practicable.

Resolution XXXI urges that the conclusions reached by the Conference regarding agricultural produce apply, whenever appropriate, to fish and marine products also, and that these subjects be considered equally by the permanent commission.

\section{OBITUARIES}

\section{Prof. Antonín Simek}

From a reference in the Chemisches Zentralblatt to a notice by Prof. F. M. Jaeger in the Chem. Weekblad (August 22, 1943; 39, 454), it is learned that Dr. Antonín Simek, professor of physical chemistry at the Masaryk University of Brno, Czechoslovakia, must have died about a year ago.

Simek, who was one of the foremost Czechoslovak physical chemists, was born at Nové Hrady in Bohemia in 1887, and studied at Prague and in Holland, where he made many life-long friends. With the establishment of the Czechoslovak Republic in 1918, he was called to the newly-founded Masaryk University and for many years was fully occupied with the equipment of his laboratories and in academic work, though he found time to conduct researches on tellurium and its oxides. During this work he observed a curious phenomenon that still remains unexplained. He fused tellurium dioxide on electrically heated platinum foil and noticed that the molten drops always move away from the negative pole and towards the positive one. The substance would even travel uphill and its velocity was proportional to the current. In attempting to repeat the experiment with selenium dioxide, which had to be heated under pressure, Simek met with a serious accident.

Besides being a physical chemist of distinction, Simek was also a keen mineralogist and he examined a number of Moravian minerals for their content of the rarer elements. Mention has been made of Simek's connexions with Holland. He also made several visits to England and used English text-books with his students. For their benefit, too, he translated A. S. Russell's "Introduction to the Study of Radioactive Substances" (1925) and Bragg's "Concerning the Nature of Things", and he made a feature of lecturing upon contemporary work in science. Most of his work was published in Czech, but he also wrote in Dutch and occasionally in English journals.

In 1926 he married his assistant, Miss Hannah 